\title{
Comparison of nutritional effects induced in chicks, rats and mice by raw soya-bean meal*
}

\author{
BY ZAFRIRA NITSAN AND A. BONDI \\ The National and University Institute of Agriculture, Rehovot, Israel \\ (Received 21 August 1964-Accepted 3 December 1964)
}

The growth-depressing effect of a raw soya-bean diet (RSD) on chicks and rats is well established (Liener, 1962). Pancreatic hypertrophy was observed in both species when given RSD (Chernick, Lepkovsky \& Chaikoff, I948; Booth, Robbins, Ribelin \& DeEds, I960; Alumot \& Nitsan, I96r). It was found that chicks given RSD showed markedly depressed proteolytic activity in the small intestine during the first hours after food ingestion (Alumot \& Nitsan, 196r). On the other hand, observations reported by Lyman \& Lepkovsky (1957) indicate an increased proteolytic activity in the small intestine of rats given RSD. In earlier work in our laboratory evidence was obtained that the chick's caecums play an important part in the utilization of raw soya-bean protein (Nitsan \& Alumot, 1963 ).

It was the purpose of this work to compare the nutritional effects of RSD on birds and mammals, and to investigate the proteolytic activity in the small intestine and caecum of both under the same conditions.

The growth-depressing action of RSD when given to rats can be overcome to a great extent by addition of antibiotics (Gebhardt \& Columbus, 1957; Borchers, 1958, I96I; Braham, Bird \& Baumann, 1959). The influence of antibiotics on chicks given RSD was therefore examined as well. The experiments were designed to study whether the action of antibiotics on growth of rats and chicks is connected with enhanced proteolysis in the small intestine or caecum, or both, or if there are any other reasons for the positive effect of antibiotics added to RSD.

The comparison of the effect of RSD on the two types of animal may contribute to a better understanding of the mechanism of the growth retardation induced by RSD.

\section{EXPERIMENTAL}

Expt $\mathrm{r}$. Measurement of the proteolytic activity in the small intestine and caecum of adult rats. Thirty adult white rats, about 6 months old, were kept from weaning on a standard rat mash that contained heated soya beans. At the beginning of the experiment, twelve of these rats continued on the heated soya-bean diet (HSD) and the remaining eighteen were transferred to RSD.

The percentage composition of the HSD and RSD was: heated or raw soya-bean meal ( $43 \%$ protein) 50 , glucose $2 I^{\circ} 5$, potato starch $2 \mathrm{I}$, sodium chloride $\mathrm{I} \cdot 2$, dicalcium

* Contribution from the National and University Institute of Agriculture, Rehovot, Israel (1964 Series, 694-E). 
phosphate $I^{\cdot} 5$, vitamin mixture 0.5 , mineral mixture $0^{\circ} 3$, soya-bean oil $4 \cdot 0$. Details about the soya-bean meal and vitamin and mineral mixtures are given by Alumot $\&$ Nitsan (196r).

The food was withheld from the rats each afternoon and given again on the following morning to ensure intensive food consumption by all rats at the same time, so that their intestines would contain about the same amounts of chyme. The measurements of the proteolytic activity were carried out $\mathrm{I}, 5$ and 8 days after transferring the rats to RSD. The rats on HSD were examined on the Ist and $5^{\text {th }}$ days of the experiment. Six rats from each treatment were killed $2 \mathrm{~h}$ after they had begun to eat, and the proteolytic activities in the small intestine and caecum were measured (compare Nitsan \& Alumot, 1960). The chyme was squeezed out and the mucus separated. The chyme was homogenized with ro vol, distilled water in an Ultra-Turrax apparatus (Janke \& Kunkel K.G., Staufen i. Br., Germany). The proteolytic activity of the homogenate was determined by the Kunitz ( 1947 ) casein digestion method, the extent of casein digestion being expressed by the increase of the extinction at $280 \mathrm{~m} \mu$ against an undigested sample of substrate.

Expt 2. The same measurements as in Expt I were made, but in this experiment mice were used. Six mice were given the same HSD and six the same RSD as in Expt I for 26 days from weaning, after which they were killed. The proteolytic activities in the small intestine and caecum were measured, as in Expt I, $2 \mathrm{~h}$ after the food had been offered.

Expt 3. Influence of antibiotics on the growth rate of chicks given soya-bean diets. Eighty White Leghorn male chicks were given a commercial mash for the ist week of life, after which they were divided into four groups according to body-weight. The four groups were given: (1) HSD; (2) HSD + antibiotics (A); (3) RSD and (4) $\mathrm{RSD}+\mathrm{A}$.

The percentage composition of HSD and RSD was: heated or raw soya-bean meal $(43 \%$ protein) $5 \circ$, glucose $19 \cdot 8$, potato starch $19 \cdot 8$, dicalcium phosphate $2 \cdot 0$, calcium carbonate 1.5 , vitamin mixture 0.4 , mineral mixture 0.5 , soya-bean oil 3.0 , cellulose 3.0 .

The antibiotics added to diets 2 and 4 were $0.1 \%$ dihydrostreptomycin and $0.1 \%$ procaine penicillin $\mathrm{G}$, which are the amounts that, when added to RSD, have been shown to give almost normal growth of rats (Borchers, I958, 196r).

Individual weights were recorded when the chicks were put on the experimental diets, and again after I week. The food intake was recorded for each group. Nitrogen retention by the chicks on the given diets was measured during periods of 6 days as previously described (Nitsan \& Alumot, 1963).

Expts 4 and 5. Effect of an antibiotic supplement on the intestinal and caecal proteolytic activity and related properties in young rats and chicks. One hundred weanling white rats and $100 \mathrm{I}$-day-old White Leghorn male chicks were divided into equal groups and given: (I) HSD; (2) HSD + A; (3) RSD and (4) RSD + A. The composition of HSD and RSD for the rats was as described in Expt $\mathrm{I}$. The diets for the chicks were as in Expt 3. The levels of the antibiotics added to diets 2 and 4 were as stated for Expt 3. The management and feeding programme for rats and chicks were as in Expts $I$ and 3 respectively. 
When the animals had been on the experimental diets for I, 3,5 and 8 days:

(I) the proteolytic activities of the intestinal and caecal contents were measured as described on p. 178 ;

(2) the $\mathrm{pH}$ of the intestinal and caecal contents was measured with a Beckman $\mathrm{pH}$-meter;

(3) the small intestine and caecum of each animal were weighed and their volumes measured by immersing the organ in a cylinder with water for a very short time and recording the volume of the displaced water;

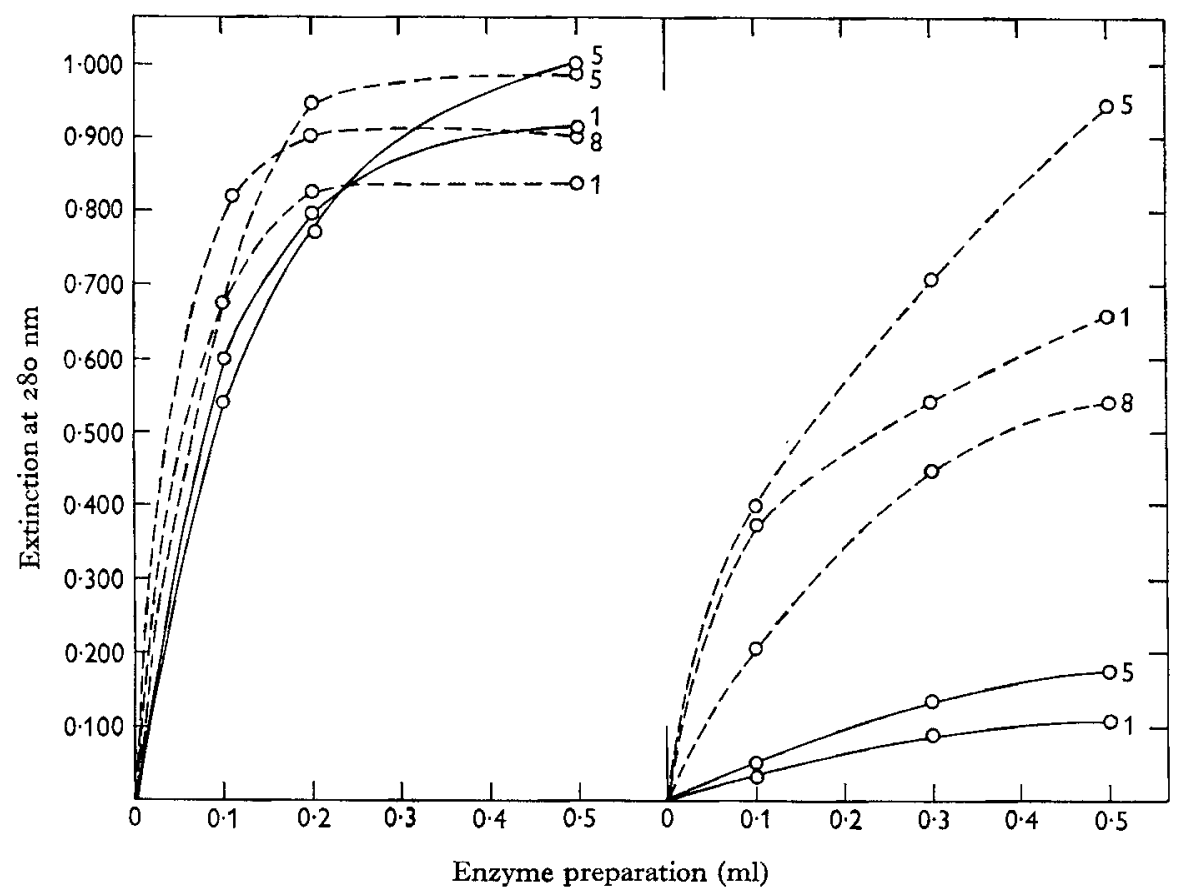

Fig. 1. Expt r. Proteolytic activity in the small intestine (left) and caecum (right) of adult rats given a heated (-) or a raw (- $(-)$ soya-bean diet. The numbers on the curves are days after transfer to the experimental diets. Each curve represents the mean result for six rats.

(4) the number of bacteria in the intestinal and caecal contents was estimated by the plate count method using Difco's plate count agar (Difco Laboratories, Detroit, Mich.);

(5) for chicks only, the pancreas was weighed.

RESULTS

Expt I. The proteolytic activities in the small intestine and caecum of adult rats on HSD and RSD are shown in Fig. I. In contrast to chicks, no depression of the proteolytic activity in the small intestine of the rat was found as a result of RSD. In the caecum, however, RSD caused a marked increase of proteolytic activity.

Expt 2. The proteolytic activities in the small intestine and caecum of mice on HSD and RSD are shown in Fig. 2. The picture seen in rats was seen also in mice; the 
proteolytic activity in the small intestine was the same with both diets. The proteolytic activity in the caecum was much greater in mice on RSD than on HSD.

Expt 3. The influence of antibiotics on body-weight, food conversion efficiency and nitrogen retention by chicks on HSD and RSD is shown in Table I. The beneficial effect of antibiotics on weight gain, expressed in $\mathrm{g}$, was the same with HSD as with

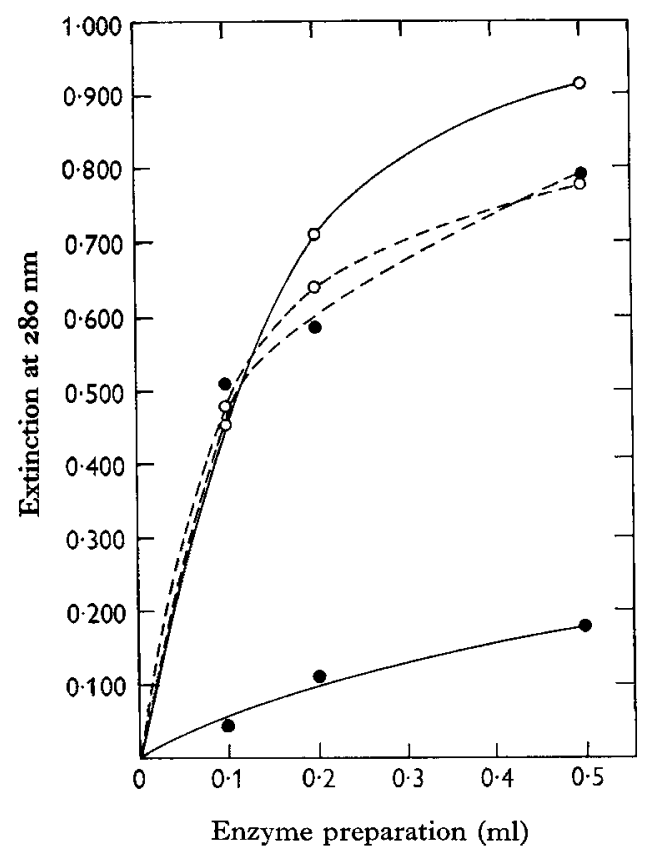

Fig. 2. Expt 2. Proteolytic activity in the small intestine $(O)$ and caecum (O) of mice given a heated $(\longrightarrow)$ or a raw $(--)$ soya-bean diet 26 days after transfer to the experimental diets. Each curve represents the mean result for six mice.

Table I. Expt 3. Effect of antibiotics $(A)$ added to heated (HSD) or raw (RSD) soyabean diets on the growth, food conversion efficiency and nitrogen retention of chicks

\begin{tabular}{lccc}
\multicolumn{1}{c}{ Diet } & $\begin{array}{c}\text { Weight } \\
\text { gain* } \\
\text { (g/day) }\end{array}$ & $\begin{array}{c}\text { g gain } / g \\
\text { food } \\
\text { consumed }\end{array}$ & $\begin{array}{c}\text { Nitrogen } \\
\text { retention } \\
(\%)\end{array}$ \\
HSD & 4.9 & 0.303 & 30.5 \\
HSD + A & 5.8 & 0.388 & 30.0 \\
RSD & 2.8 & 0.179 & $21 \cdot r$ \\
RSD + A & 3.6 & 0.222 & 32.2 \\
LSD at $P<0.05$ & 0.55 & &
\end{tabular}

* Mean values for daily weight gain from I to 2 weeks of age of twenty chicks.

$+\frac{(\mathrm{N} \text { in feed })-(\mathrm{N} \text { in excreta) }}{(\mathrm{N} \text { in feed })} \times 100$.

$\ddagger$ Least significant difference: differences larger than the LSD are considered significantly different.

RSD, but when the gain was calculated as a percentage increase over the controls it was greater when the antibiotics were added to RSD $(28.5 \%)$ than to HSD (18.3\%). However, the chicks kept on RSD supplemented with antibiotics did not reach the 
body-weight of those kept on HSD. Supplementation of RSD and HSD with antibiotics caused an improved food utilization by chicks in comparison with their performance on the respective diets without antibotics. The addition of antibiotics did not change the nitrogen retention of chicks on HSD, but raised that of chicks on RSD to that of chicks on HSD.

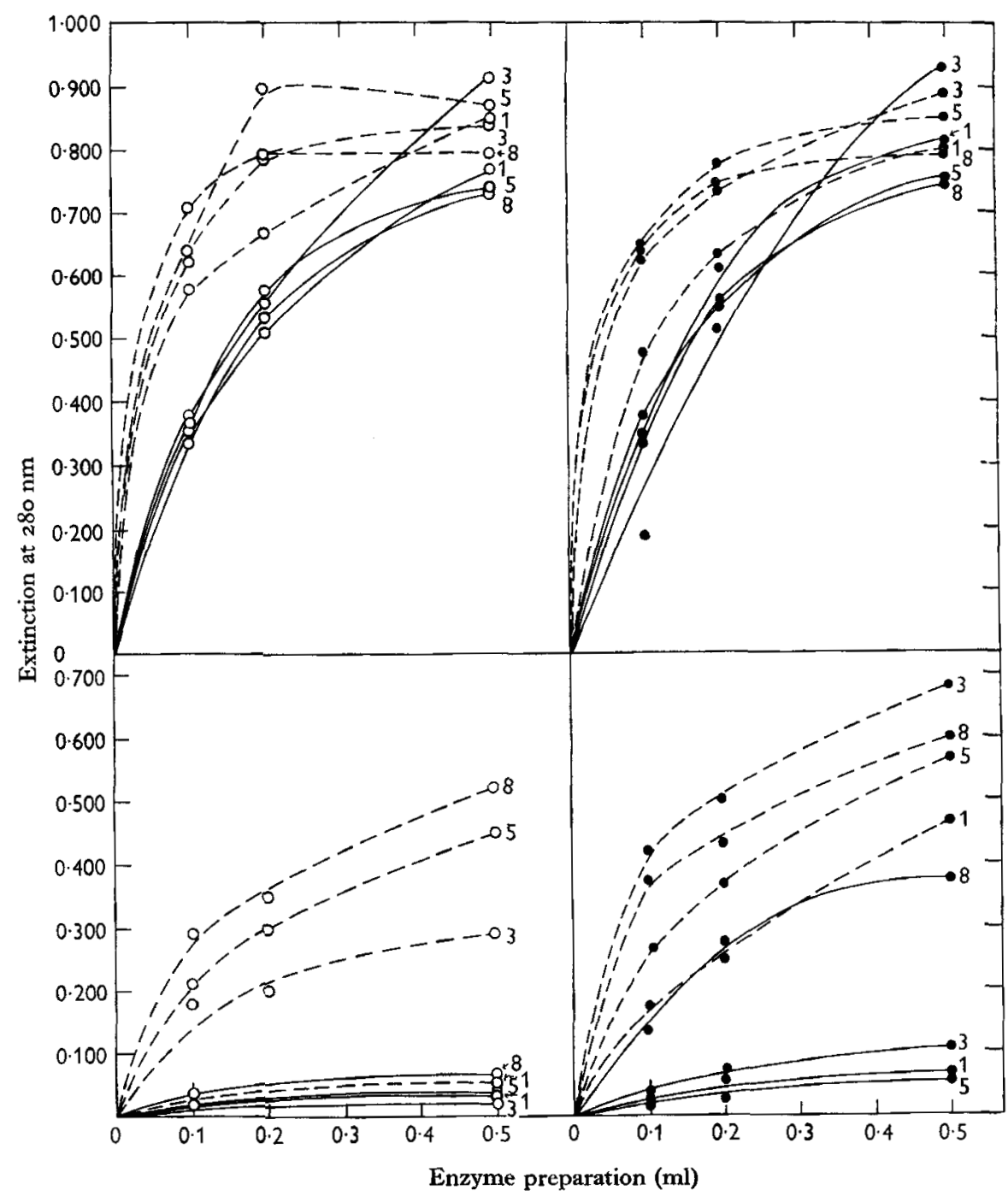

Fig. 3. Expt 4. Proteolytic activity in the small intestine (upper) and caecum (lower) of weanling rats given a heated (-) or a raw (-- ) soya-bean diet with ()$\left.^{-}\right)$or without $(0)$ antibiotics. The numbers on the curves are days after the transfer to the experimental diets. Each curve represents the mean result for six rats.

Expts 4 and 5. The effect of antibiotic supplementation of HSD and RSD on the proteolytic activity in the small intestine and caecum of weanling rats is shown in Fig. 3. The addition of antibiotics to either HSD or RSD did not cause any change in 
the proteolytic activity in the small intestine. In the caecum, however, addition of antibiotics to RSD enhanced proteolytic activity and caused it to begin earlier than when RSD was given without antibiotics; in rats on RSD, caecal proteolytic activity

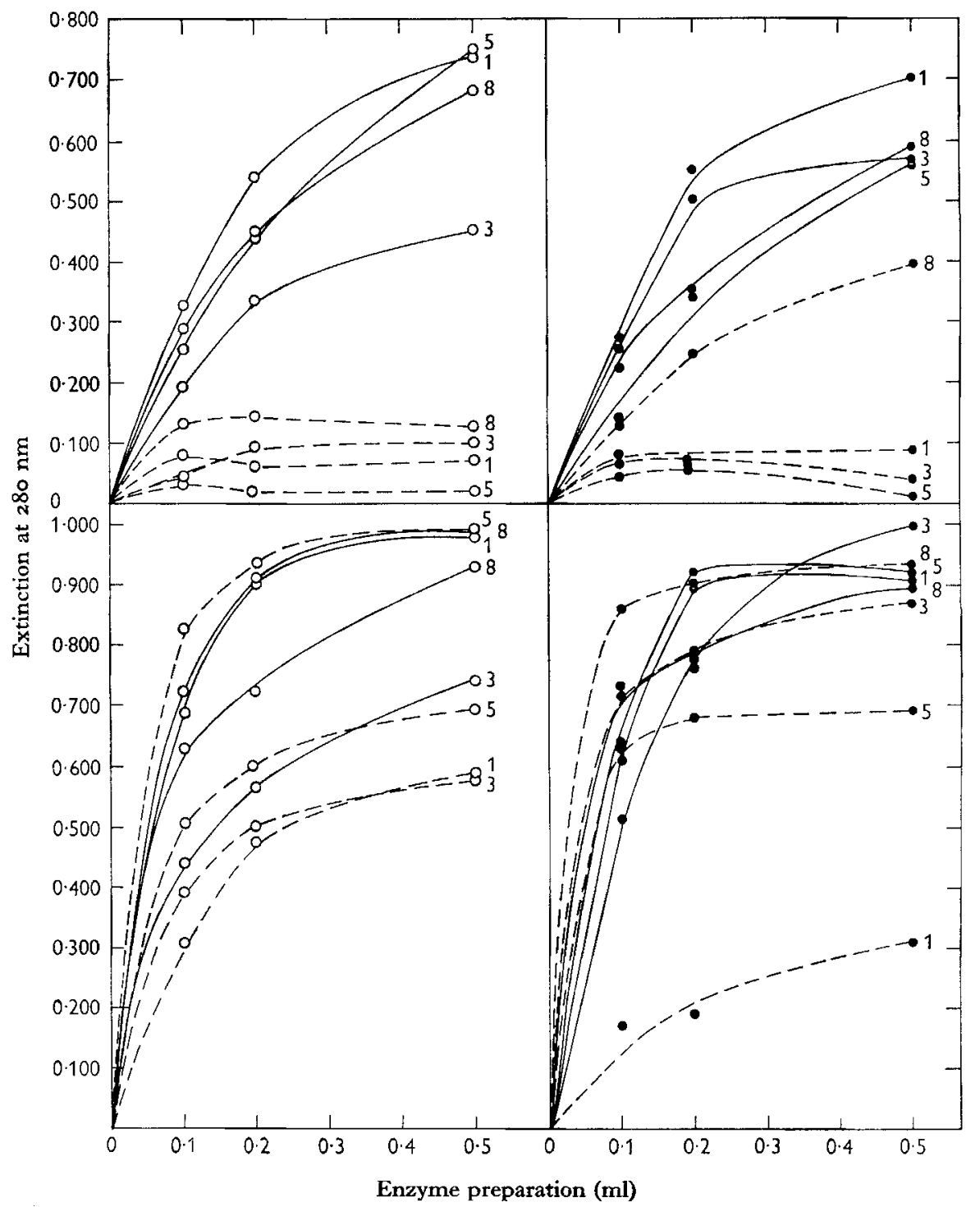

Fig. 4. Expt 5. Proteolytic activity in the small intestine (upper) and caecums (lower) of chicks given a heated (-) or a raw (- - ) soya-bean diet with (O) or without $(O)$ antibiotics. The numbers on the curves are days after transfer to the experimental diets. Each point represents the mean result for six chicks.

could be observed only from the $3^{\text {rd }}$ day, whereas in those on RSD + A marked proteolytic activity was found from the Ist day of the experiment. Moreover, the level of proteolytic activity in the caecum of rats on RSD + A was always somewhat higher than for rats on RSD. 
Table 2. Expts 4 and 5. Effect of antibiotics $(A)$ added to heated (HSD) or raw (RSD) soya-bean diets, on the $p H$ of the pooled intestinal and pooled caecal contents of groups of six chicks and of six rats

(Mean of values recorded $\mathrm{I}, 3,5$ and 8 days after transfer to the experimental diets)

\begin{tabular}{lcccc}
\multicolumn{1}{c}{ Chicks } & & \multicolumn{2}{c}{ Rats } \\
Diet & $\overbrace{\begin{array}{c}\text { Small } \\
\text { intestine }\end{array}}^{\text {Caecum }}$ \\
HSD & 7.45 & 5.75 & 7.30 & 5.25 \\
HSD + A & 7.47 & 5.30 & 7.13 & 5.55 \\
RSD & 7.36 & 6.30 & 6.88 & 5.31 \\
RSD + A & 7.72 & 5.93 & 7.11 & 5.52 \\
LSD* at $P<0.05$ & 0.36 & 0.30 & 0.46 & 0.27
\end{tabular}

* See footnote to Table I.

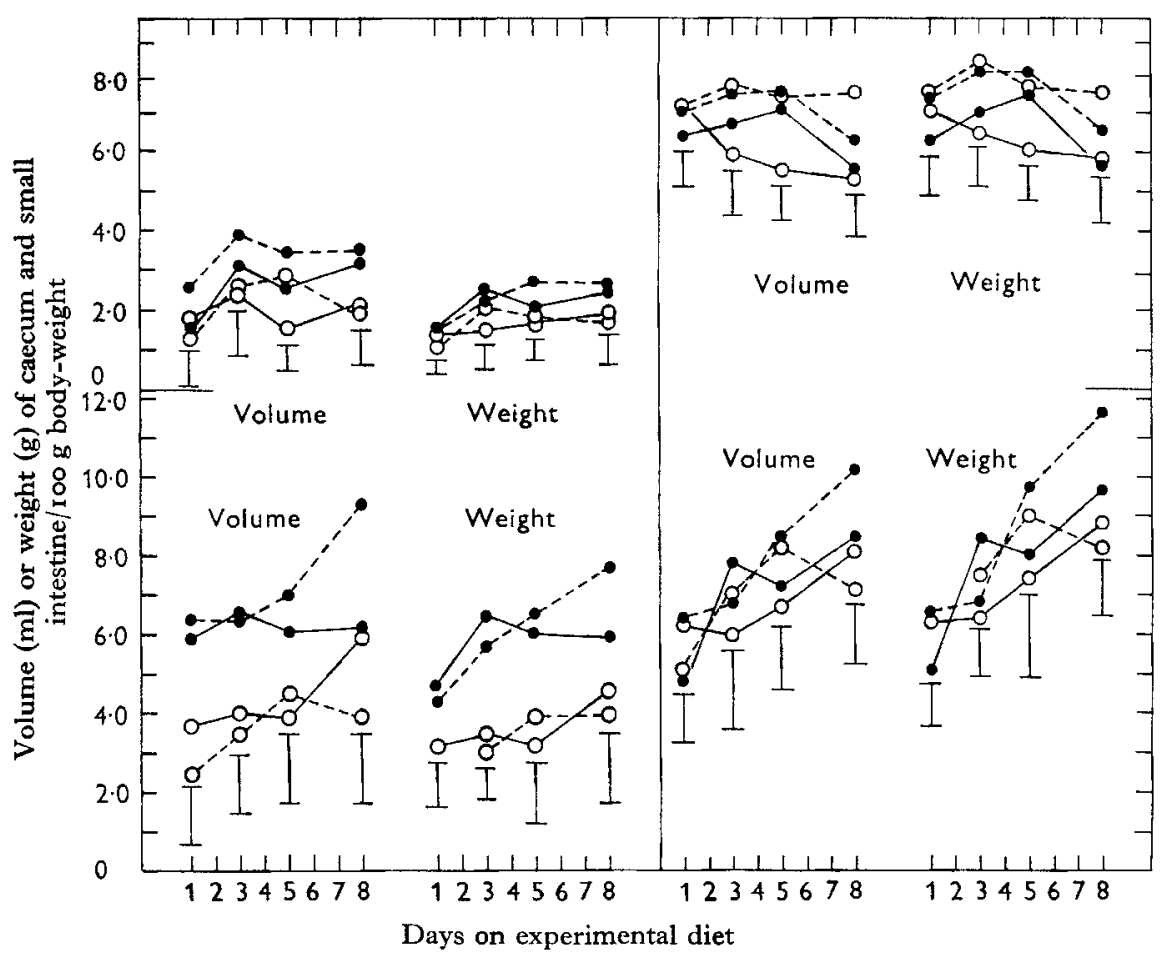

Fig. 5. Expts 4 and 5. Volume and weight of caecum (left) and small intestine (right) (calculated on the basis of $100 \mathrm{~g}$ body-weight) of rats (upper) and chicks (lower) given a heated $(-)$ or a raw (- - ) soya-bean diet with $(0)$ or without $(0)$ antibiotics. Each point is the mean result for six animals. The vertical lines correspond to the least significant difference $(P<0.05)$ at each time.

On HSD, almost no proteolytic activity was found in the caecum throughout the experiment. However, when the HSD was supplemented with antibiotics, considerable proteolytic activity was found in the caecum on the 8th day of the experiment.

The effect of antibiotic supplementation of HSD and RSD on the proteolytic 
Table 3. Expts 4 and 5. Effect of antibiotics $(A)$ added to heated (HSD) or raw $(R S D)$ soya-bean diets on the bacterial count in the intestinal and caecal contents of chicks and rats

(Mean count/g mixed contents for groups of six animals)

\begin{tabular}{lccccc}
\multirow{2}{*}{ Diet } & $\overbrace{\begin{array}{c}\text { Small } \\
\text { intestine }\end{array}}$ Chicks & $\overbrace{\begin{array}{c}\text { Small } \\
\text { intestine }\end{array}}^{\text {Caecums }}$ & Caecum \\
HSD & $27 \times 10^{8}$ & $18 \times 10^{8}$ & & $\begin{array}{c}90 \times 10^{8} \\
(2)\end{array}$ & $14 \times 10^{7}$ \\
& $(4)$ & $(4)$ & $(3)$ \\
HSD +A & $40 \times 10^{8}$ & $84 \times 10^{8}$ & & $45 \times 10^{7}$ & $64 \times 10^{8}$ \\
& $(4)$ & $(4)$ & $(2)$ & $(3)$ \\
RSD & $31 \times 10^{6}$ & $22 \times 10^{8}$ & & $13 \times 10^{7}$ & $14 \times 10^{7}$ \\
& $(4)$ & $(4)$ & $(2)$ & $(3)$ \\
RSD+A & $13 \times 10^{8}$ & $13 \times 10^{8}$ & $15 \times 10^{8}$ & $45 \times 10^{8}$ \\
& $(4)$ & $(4)$ & $(2)$ & $(3)$
\end{tabular}

Numbers in parentheses show how the counts were made: 4 , every day of the experiment; 3 , the last 3 days; 2 , the last 2 days.

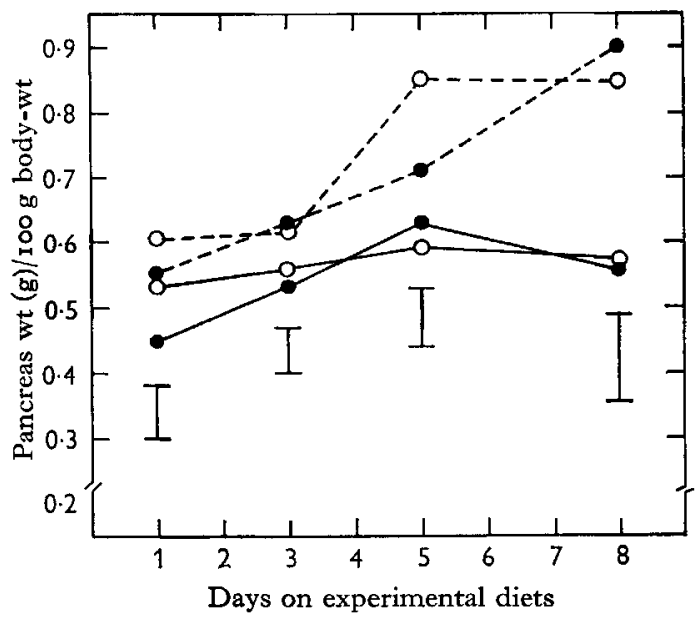

Fig. 6. Expt 5. Ratio, pancreas weight: body-weight of chicks given a heated (- $\rightarrow$ ) or a raw $(--)$ soya-bean diet with $(O)$ or without $(O)$ antibiotics. Each point represents the mean result for six chicks. The vertical lines correspond to the least significant difference $(P<0.05)$ at each time.

activity in the small intestine and caecum of young chicks is shown in Fig. 4. RSD inhibited the proteolytic activity in the small intestine, as previously reported (Alumot $\&$ Nitsan, 196I). The addition of antibiotics appeared to help the chicks to overcome this inhibition by the 8th day, when the chicks on RSD $+\mathrm{A}$ had a level of proteolytic activity in their intestines approaching that of chicks on HSD, although those on RSD without antibiotics had not. No effect was noted from antibiotic supplementation of HSD. On the Ist day, the proteolytic activity in the caecum of chicks given RSD + A was somewhat lower than in those of chicks given RSD, but on the subsequent days it was about the same in both groups. 
The mean $\mathrm{pH}$ of the intestinal and caecal contents of chicks and rats on HSD and RSD, with and without antibiotics, is given in Table 2 . The addition of antibiotics to the diets caused a reduction of the $\mathrm{pH}$ of the caecal contents of chicks, whereas the opposite was true in rats. There was no consistent effect on intestinal $\mathrm{pH}$.

The addition of antibiotics to both RSD and HSD increased the volume and weight of the caecum of chicks and rats (Fig. 5). The influence upon the small intestine was not as regular and consistent as that upon the caecum (Fig. 5). The percentage of dry matter in the contents of the intestine and caecum of the rats was almost unchanged, whether by the kind of soya-bean meal or by the presence of antibiotics, being between 21.2 and $22.6 \%$ in the small intestine, and between 20.0 and $22.6 \%$ in the caecum.

The bacterial counts in the intestinal and caecal contents of chicks and rats are given in Table 3 . The antibiotics increased the total count of bacteria in the intestine and caecum of rats with both RSD and HSD. In chicks, an effect was not noticed in the intestine. In the caecums an increased bacterial count was noticed only when antibiotics were added to RSD.

The pancreas: body-weight ratio in chicks on the four diets is shown in Fig. 6. The addition of antibiotics to HSD or RSD did not change the ratio.

\section{DISCUSSION}

Whereas RSD greatly depressed proteolytic activity in the small intestine of young chicks during the first hours after ingestion of food, it did not affect the intestinal proteolytic activity in rats and mice during this period. The reason for this species difference might be the sensitivity of certain soya-bean trypsin inhibitors towards acid and peptic digestion in the mammal's stomach. This is consistent with observations of Birk \& Gertler (196I) and of Birk (196I), that the antitryptic activities of crude and purified trypsin inhibitors, raw soya-bean meal and certain fractions of raw soyabean meal are markedly depressed by treatment with acid and pepsin. This peptic digestion probably destroys or inactivates only one of the inhibitors present in RSD (Kassel \& Laskowski, I956). It seems that the remaining active factor is sufficient to cause pancreas hypertrophy. The enlarged pancreas presumably secretes increased amounts of enzymes, so that no inhibition of proteolytic activity in rat intestine is noticed. The peptic action occurring in the chicken gizzard is slight (Sturkie, 1954; Alumot \& Nitsan, 196I) and does not seem to affect the antitryptic activity of RSD passing through the gizzard.

The different effects caused by the giving of antibiotics to chicks and to rats fed on RSD and HSD, respectively, support the views expressed by Alumot \& Nitsan (196I) and by Booth et al. ( 1960$)$ concerning the different mechanism of growth retardation in chicks and rats induced by RSD. According to these views the growth retardation by RSD in chicks is mainly a result of inhibited proteolysis and of loss of endogenous nitrogen induced by pancreatic hypertrophy, whereas in rats only the latter factor seems to be of importance.

Addition of antibiotics has a greater effect on growth rate and food conversion efficiency in rats and in chicks with RSD than with HSD (Borchers, I96I). Moreover, 
the action of antibiotics in lessening growth retardation was more striking in RSD-fed rats than in RSD-fed chicks. Pancreatic hypertrophy, which is the main factor depressing growth of rats fed on RSD according to Booth et al. (1960), is eliminated by the addition of antibiotics (Goldberg \& Guggenheim, I964).

On the other hand, according to the results of the work now reported, the pancreatic hypertrophy of chicks fed on RSD is not affected by antibiotics, and the intestinal proteolytic activity is raised only to a small extent and at a later period after the chicks have been transferred to RSD. Therefore, the smaller effect of antibiotics on chicks fed on RSD is understandable.

As pointed out above, the caecum participates in the utilization of raw soya-bean protein. Consequently, the rise in proteolytic activity in the caecum of rats induced by addition of antibiotics to RSD may also contribute to the positive effect of antibiotics in this instance. No effect of antibiotics on caecal proteolysis of chicks fed on RSD was observed, a finding consistent with the small influence of antibiotics on the growth rate of such chicks.

Further, supplementation of RSD or HSD with antibiotics resulted in chicks and in rats in some additional effects similar to those observed in general when the food efficiency of diets has been improved by the use of antibiotics. The greater size and weight of the filled caecums of chicks and rats receiving antibiotics points to a retardation in food transfer, with consequent prolonged action of the proteolytic enzymes on the food. Observations on the infuence of antibiotics on the volume and weight of filled intestines and caecums of young animals receiving different kinds of diet have been reported by others (Anderson, Cunningham \& Slinger, 1952; Lee \& Moinuddin, 1958).

Further, the fact that the bacterial count was always higher in the rat intestine and caecum on both diets when supplemented with antibiotics, and in chick caecums when RSD was supplemented with antibiotics, leads to the possible assumption that not only higher proteolytic activity, but also other bacterial activities of benefit to the host animal, such as deamination or protein biosynthesis, may be enhanced (Michel, 196r ; Romoser, Shorb \& Combs, 1952). Increase of bacterial count resulting from antibiotic supplementation of the diet has been observed in some instances by other workers (Sieburth, Jezeski, Hill \& Carpenter, 1954).

\section{SUMMARY}

I. The proteolytic activity in the small intestine and caecum of rats and mice on heated (HSD) and raw (RSD) soya-bean diets was studied and compared with earlier results obtained with chicks. It was found that RSD did not have any measurable effect on intestinal proteolytic activity in rats and mice, in contrast to a considerable inhibition in chicks.

2. Whereas a considerable proteolytic activity was found in caecums of chicks on both RSD and HSD, the proteolytic activity in the caecum of rats fed on RSD was increased in comparison with the very small proteolytic activity with HSD.

3. Supplementation of RSD and HSD with antibiotics caused an increased growth 
rate of, and improved food utilization by, chicks in comparison with their performance on the respective diets without antibiotics. However, the chicks kept on RSD supplemented by antibiotics did not reach the body-weight of those kept on HSD.

4. There was no difference in nitrogen retention between the chicks on HSD with or without antibiotics, but the chicks on RSD with antibiotics retained much more nitrogen than did those on RSD alone.

5. The addition of antibiotics did not exert any marked influence on the intestinal or caecal proteolytic activity in chicks and rats on HSD. In rats on RSD, the addition of antibiotics enhanced the proteolytic activity of the caecal contents. In chicks on RSD with antibiotics, the inhibition of intestinal proteolytic activity observed with RSD was overcome by the 8th day of the experiment, whereas such an effect was not found in chicks fed on RSD alone.

6. The probable reasons for the difference in the influence of RSD on rats, mice and chicks are discussed.

We wish to thank Dr E. Alumot for her helpful suggestions, and gratefully to acknowledge the technical assistance of Mrs M. Noiman, Miss C. Genige and Mr E. Mandel. We are indebted to Professor K. Guggenheim, Jerusalem, for providing us with unpublished results of his experiments.

\section{REFERENCES}

Alumot, E. \& Nitsan, Z. (1961). F. Nutr. 73, 71.

Anderson, G. W., Cunningham, J. D. \& Slinger, S. J. (1952). F. Nutr. 47, 75.

Birk, Y. (196r). Biochim. biophys. Acta, 54, 378 .

Birk, Y. \& Gertler, A. (1961). 7. Nutr. 75, 379.

Booth, A. N., Robbins, D. J., Ribelin, W. E. \& DeEds, F. (ז960). Proc. Soc. exp. Biol., N. Y., 104, 681. Borchers, R. (1958). F. Nutr. 66, 229.

Borchers, R. (196r). F. Nutr. 75, 330 .

Braham, I. H., Bird, H. R. \& Baumann, C. A. (1959). J. Nutr. 67, 149.

Chernick, S. S., Lepkovsky, S. \& Chaikoff, J. L. (1948). Amer. F. Physiol. 155, 33.

Gebhardt, H. \& Columbus, A. (1957). Z. Tierernähr. I2, 366.

Goldberg, A. \& Guggenheim, K. (1964). Arch. Biochem. Biophys. ro8, 250.

Kassel, B. \& Laskowski, M. (1956). F. biol. Chem. 219, 203.

Kunitz, M. (1947). F. gen. Physiol. 30, 291.

Lee, H. W. T. \& Moinuddin, J. F. (1958). Amer. F. Physiol. 192, 421.

Liener, J. E. (1962). Amer. F. clin. Nutr. I1, 281.

Lyman, R. L. \& Lepkovsky, S. (1957). J. Nutr. 62, 269.

Michel, M. (1961). Ann. Biol. anim. Biochim. Biophys. 1, I6.

Nitsan, Z. \& Alumot, E. (1960). Bull. Res. Coun. Israel, 9 A, 23.

Nitsan, Z. \& Alumot, E. (1963). F. Nutr. 80, 299.

Romoser, G. L., Shorb, M. S. \& Combs, G. F. (1952). Poult. Sci. 31, 932.

Sieburth, J. McN., Jezeski, J. J., Hill, E. G. \& Carpenter, L. E. (1954). Poult. Sci. 33, 753.

Sturkie, P. D. (1954). Avian Physiology. Ithaca, NY: Comstock Publishing Co. 